\title{
Experimental research on the interactions between some anxiolytics and dietary sodium monoglutamate
}

\author{
Buzescu Anca, Cristea Nicoleta Aurelia*, Chiriac Alexandra, Chiriță C \\ University of Medicine and Pharmacy "Carol Davila", Bucharest, România
}

\begin{abstract}
Objectives: Monosodium glutamate, the salt of glutamic acid, is largely used as a flavour enhancer (E621). In this study, we determine if monosodium glutamate, after repeated oral administration, can induce any degree of anxiety. Taking into account the interdependence between glutamate and GABA neurotransmissions, we studied the possible interactions of monosodium glutamate with some representatives belonging to benzodiazepines therapeutical class, diazepam and alprazolam, used as first line therapy for the treatment of anxiety. Methods: For determining the degree of anxiety, the specific cross-labyrinth test was used. The medium time spent in the closed-arms of the crosslabyrinth is correlated with increased anxiety and the medium time spent in the opened arms is correlated with a low degree anxiety. NMRI adult mice received $300 \mathrm{mg} / \mathrm{kg}$ monosodium glutamate for 21 days, dose representing 1/50 from mice LD50 (15000mg/kg) and twice the maximum admitted dose/ day for human. Results: When compared to control group, the group receiving monosodium glutamate, showed a not statistically significant slight increase in the degree of anxiety. The groups receiving benzodiazepines presented a significant reduction of the degree of anxiety, proving their anxiolytic effect. The groups receiving glutamate and diazepam or alprazolam, showed a lower reduction of the degree of anxiety, than group receiving only benzodiazepines, phenomenon which proves an antagonism between glutamate and the anxiolytics used in this study. Conclusions: The oral administration of monosodium glutamate increases slightly, not statistically significant, the degree of anxiety in mice and significantly alters the response to the benzodiazepines therapy, reducing the effect for both alprazolam and diazepam.
\end{abstract}

Keywords: monosodium glutamate, E621, anxiolytics antagonism, NMRI mice, cross-labyrinth test

Received: 2 June 2014 / Accepted: 1 December 2014

\section{Introduction}

Monosodium glutamate (MSG, E621,), the salt of glutamic acid (GLU), is largely used as flavour enhancer [1, 2]. Due to its' specific savoury taste „umami”, it induces a "costumer's loyalty”. It should be noted that corticostriatal glutamatergic transmission has role in stimulating the release of dopamine in the striatum, with implication in both the initiation and expression of addiction-related behaviors in addiction [3]. In our previous work, we demonstrated the addictive potential of MSG when given daily, in drinking water, to NMRI mice [4]. Thus, in human, the admitted daily intake of $150 \mathrm{mg} \mathrm{MSG/kg} \mathrm{[2]} \mathrm{could} \mathrm{be}$ surpassed.

Also, GLU represents the most important excitatory neurotransmitter, controlling synaptic excitability and plasticity in various brain circuits, including those involved in anxiety $[5,6]$.

Anxiety refers to fear. It is an adaptive reaction to a threat or psychological distress, with a leading role in protecting the body from aggressions. In excess, anxiety can cause distress, interfering with daily living. Anxiety disorders are among the most common mental disorders both in Europe, as in United States, with a significant increase in the number of diagnosed patients in each year. Anxiety disorders include generalized anxiety disorders, social pho-

${ }^{*}$ Correspondence to: Cristea Nicoleta Aurelia

E-mail: anicoletacristea@yahoo.com bias, specific phobias, post-traumatic stress disorder, panic attacks [5].

Studies on the pathophysiology of anxiety have proven an intensification of glutamatergic transmission [6,7]. Nuclear imaging studies have shown in patients suffering from anxiety disorders, that brain regions with high glutamate concentration (hippocampus, amigdalla, etc) had structural changes or hyperactivity $[8,9]$.

One of the most used standard first-line anxiety treatments include anxiolytics from benzodiazepines therapeutical class, agonists of GABA receptors, with a high response rate for most of patients [10].

Given this data, we tried to determine if GLU, when administred orally as MSG, can influence stress-induced behaviour and the degree of anxiety. Also, taking into account the interdependence between GABA-glutamate neurotransmissions, we studied the possible interactions of MSG with some representatives belonging to benzodiazepines therapeutical class, diazepam and alprazolam.

\section{Materials and methods}

\section{Materials}

Monosodium Glutamate (MSG = E 621) was purchased from Sigma-Aldrich. Diazepam was obtained from Terapia (Romania), and alprazolam from Labormed (Romania).

Cross-labyrinth (plus-maze) Ugo Basile 40142/3. 


\section{Methods}

The cross-labyrinth test is an elevated maze shaped like a plus sign. Two opposing arms are enclosed by high walls and the crossing arms are opened. The medium time (Tm) spent in the closed-arms of the cross-labyrinth is correlated with increased anxiety and the medium time spent in the opened arms is correlated with a low degree anxiety. Mice were placed in the center of the maze facing every time the same closed arm. The time spent in each type of arm was measured during 5-min tests.

\section{Experimental animals}

60 NMRI adult mice, weighing $25 \pm 2 \mathrm{~g}$, were purchased from UMF biobase, Bucharest. They were housed in an individualized ventilated cage system, with free access to water and granulated food. The temperature ranged between $20-22^{\circ} \mathrm{C}$ and the relative humidity was maintained at $35-45 \%$.

All procedures were carried out in accordance with the Directive 2010/63/UE 1.01.2013 - protection of animals used for experimental and other scientific purposes.

\section{Statistical analysis}

Statistical analysis was performed using GraphPad Prism version 5.00 for Windows, GraphPad Software, San Diego California USA. The type of distribution of the animal response was established with D'Agostino \& Pearson test. The statistical analysis used parametrical t Student test (for normal distribution) or nonparametrical Wilcoxon test (for abnormal distribution). The results were expressed as mean \pm standard deviation.

\section{Experimental protocol}

The mice were divided in 6 working groups of 10 mice each. Each group received for 21 days:

- Group I, III, and V: distilled water $0,1 \mathrm{ml} / 10 \mathrm{~g}$ p.o.

- Group II, IV and VI: MSG $300 \mathrm{mg} / \mathrm{kg}$ (solution $3 \%$ ) p.o.

The MSG dose $(300 \mathrm{mg} / \mathrm{kg})$ represents $1 / 50$ from mice LD50 $(15000 \mathrm{mg} / \mathrm{kg})$ and is twice the maximum admitted dose per day for human $(150 \mathrm{mg} / \mathrm{kg})$.
After 21 days, the animals received for another three days (in days 22, 23, 24):

- Group I (control group): distilled water $0,1 \mathrm{ml} / 10 \mathrm{~g}$ p.o.

- Group II: MSG 300 mg/kg (solution 3\% ) p.o.

- Group III: Diazepam $2 \mathrm{mg} / \mathrm{kg}$ (solution 0,02\%) p.o.

- Group IV: MSG 300 mg/kg (solution 3\% ) p.o. + Diazepam $2 \mathrm{mg} / \mathrm{kg}$ (solution 0,02\%) p.o.

- Group V: Alprazolam 0,75 mg/kg (solution 0,0075\%) p.o.

- Group VI: MSG 300 mg/kg (solution 3\% ) p.o. + Alprazolam 0,75 mg/kg (solution 0,0075\%) p.o.

In days 22, 23, 24, one hour after administration, all groups were submitted to cross-labyrinth test.

\section{Results}

The medium time ( $\mathrm{Tm}$ ) spent in the closed-arms of the cross-labyrinth by each group is given in table 1 .

Tm spent in the closed arms slightly increased within each group, from day 1 to day 3, but this increase had no statistical relevance.

The percent variations of medium time spent in the closed arms of the cross-labyrinth when compared to control group and the statistical significance are illustrated in figure 1.

For the group receiving MSG (group II), a slight increase of medium time spent in the closed arms of the cross-labyrinth (representing an increase of anxiety) when compared to control group (I) is noticed (6\%, $9 \%, 8 \%$, in the tree days of research), but the variation is not statistically significant.

Both diazepam and alprazolam groups (III, V) present a significant reduction of the medium time spent in the closed arms of the cross-labyrinth when compared to control group, proving their anxiolytic effect, more intense for diazepam $(-44 \%,-39 \%,-38 \%$; all $\mathrm{p}<0,001)$.

For the groups pretreated with MSG for 21 days (groups IV, VI), after administration of diazepam or alprazolam, a decrease in the medium time spent in the closed arms of the cross-labyrinth when compared to control group, is noticed (significant for the association with

Table I. Medium time (Tm) spent in the closed arms of the cross-labyrinth, for all groups

\begin{tabular}{|c|c|c|c|c|c|}
\hline \multirow[b]{2}{*}{ Group } & \multicolumn{5}{|c|}{ Tm in closed arms (seconds) $\pm \mathrm{DS}$} \\
\hline & Day 1 & Day 2 & $\begin{array}{c}\Delta \% \\
\text { Day } 2 \text { from Day } 1\end{array}$ & Day 3 & $\begin{array}{c}\Delta \% \\
\text { Day } 3 \text { from Day } 1\end{array}$ \\
\hline Distilled Water & $234.2 \pm 28.32$ & $235.8 \pm 31.81$ & $\begin{array}{c}0.68 \% \\
\text { Ns }(p>0.05)\end{array}$ & $246.2 \pm 33.27$ & $\begin{array}{c}5.12 \% \\
\text { Ns }(p>0.05)\end{array}$ \\
\hline $\begin{array}{l}\text { II } \\
\text { MSG }\end{array}$ & $249 \pm 28.39$ & $257.9 \pm 30.63$ & $\begin{array}{c}3.57 \% \\
\text { Ns }(p>0.05)\end{array}$ & $265.5 \pm 29.55$ & $\begin{array}{c}6.63 \% \\
\text { Ns }(p>0.05)\end{array}$ \\
\hline $\begin{array}{l}\text { III } \\
\text { Diazepam }\end{array}$ & $131.9 \pm 31.40$ & $142.9 \pm 30.37$ & $\begin{array}{c}8.33 \% \\
\text { Ns }(p>0.05)\end{array}$ & $153.4 \pm 48.13$ & $\begin{array}{c}16.30 \% \\
\text { Ns }(p>0.05)\end{array}$ \\
\hline $\begin{array}{l}\text { IV } \\
\text { MSG+ Diazepam }\end{array}$ & $180.4 \pm 26.65$ & $201.40 \pm 37.63$ & $\begin{array}{c}11.64 \% \\
\text { Ns }(p>0.05)\end{array}$ & $200.70 \pm 19.99$ & $11.22 \%$ \\
\hline $\begin{array}{l}\text { V } \\
\text { Alprazolam }\end{array}$ & $188.20 \pm 26.54$ & $188.80 \pm 32.19$ & $\begin{array}{c}0.32 \% \\
\text { Ns }(p>0.05)\end{array}$ & $201.70 \pm 23.53$ & $\begin{array}{c}7.17 \% \\
\text { Ns }(p>0.05)\end{array}$ \\
\hline $\begin{array}{l}\text { VI } \\
\text { MSG + Alprazolam }\end{array}$ & $223.60 \pm 28.25$ & $231.60 \pm 34.46$ & $\begin{array}{c}3.57 \% \\
\text { Ns }(p>0.05)\end{array}$ & $235.60 \pm 33.19$ & $\begin{array}{c}5.37 \% \\
\text { Ns }(p>0.05)\end{array}$ \\
\hline
\end{tabular}

DS - standard deviation; ns - with no statistical significance; $\Delta \%=\left(\right.$ Tm Day2- Tm Day1) ${ }^{\star} 100 / T m$ Day1 or $\Delta \%=(\operatorname{Tm} \text { Day3- Tm Day1 })^{\star} 100 / T m$ Day1 


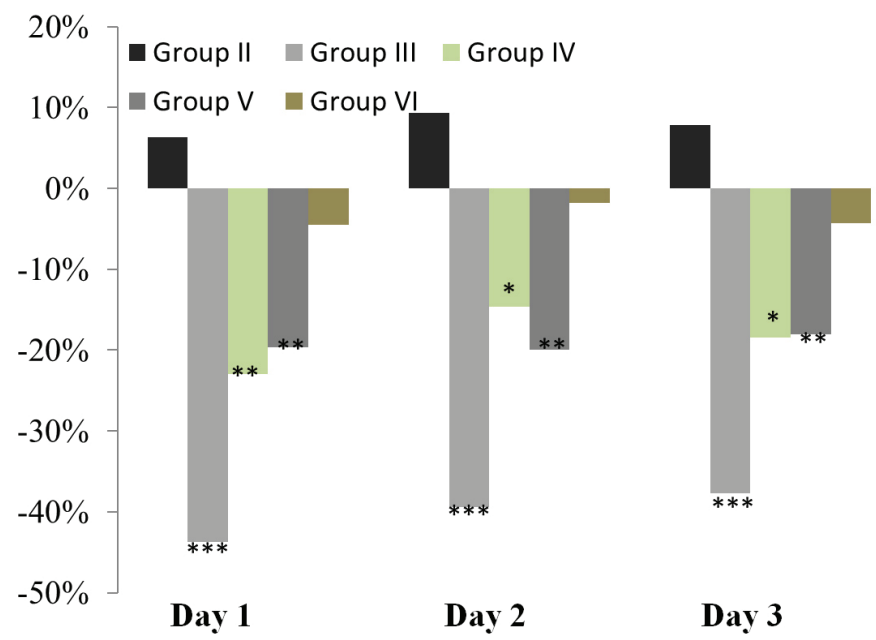

Fig. 1. The percent variations of medium time spent in the closed arms of the cross-labyrinth compared to control group

diazepam, without significance for the association with alprazolam).

The medium time spent in the closed-arms was significantly higher for the groups receiving association MSG+diazepam or MSG+alprazolam (percentual increases $37 \%, 41 \%$, $31 \%$, respectively $19 \%, 23 \%, 17 \%)$, than for the groups receiving only benzodiazepines (diazepam or alprazolam, repectively), as illustrated in figures 2 and 3. This suggests an significant antagonism between MSG and the anxiolytics used in the study.

\section{Discussion}

The results of this research proved our hypothesis on the possible interactions of the food additive MSG (E621) used as flavor enhancer, with drugs that interfere with excitatory glutamatergic transmission, such as anxiolytics belonging to benzodiazepines class, which are agonists of GABA receptors.

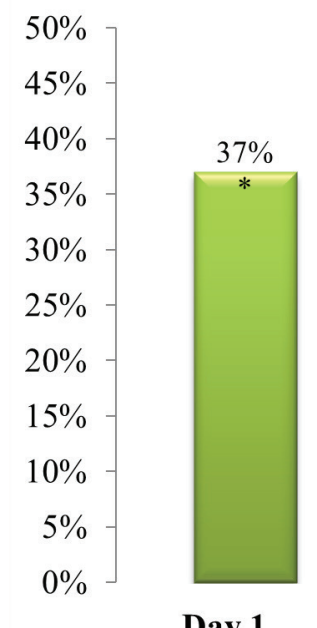

Day 1

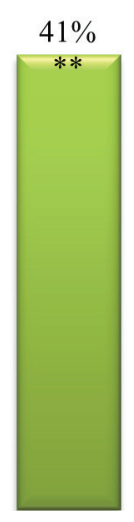

Day 2

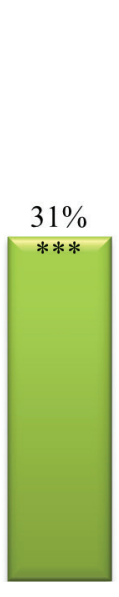

Day 3
Fig. 2. The medium time spent in the closed-arms for the group receiving association $M S G+$ diazepam versus receiving only benzodiazepines
The chosen method for this research was the induction of anxiety using the cross-labyrinth test, an elevated maze shaped like a plus sign with two opposing arms: the arms enclosed by high walls and the total opened crossing arms. This choice was based on the fact that the cross-labyrinth test was particularly used by other authors in studying the anxiolytic effect of benzodiazepines [11-13].

Tm spent in the closed arms slightly increased within each group, from day 1 to day 3 , but this increase had no statistical relevance. This unsignificant increase, which is also seen for the control group, is specific to the test and is due to the stress and anxiety generated by the investigation of the elevated opened arms. These results are in accordance with the information found in literature that in stress conditions, the excessive release of hippocampal glutamate occurs. For example, the stress caused in rats, through other anxiety tests and despair such as forced swimming or repeating the imobilisation test, leads to an increase of glutamate in hippocampus and prefrontal cortex [6].

For the group treated with MSG for 21 days (group II), a slight increase of medium time spent in the closed arms of the cross-labyrinth (representing an increase of anxiety) when compared to control group (I) is noticed. This anxiogenic effect resulted from long term dietary MSG intake, was expected according to our working hypothesis and to the present knowledge regarding the excitatory glutamatergic transmission. In accordance with the information found in literature, there have been people who have accused a number of symptoms associated with MSG consumption (known as "Chinese restaurant syndrome") such being: sudden mood change sand panic attacks $[14,15]$. Basic research ghives scientific support proving that NMDA glutamatergic receptors and mGluR7 glutamatergic receptors have been linked with anxiety. Mice with various NMDA glutamatergic receptors subunits deleted were less anxious (plus-maze test) and showed spatial

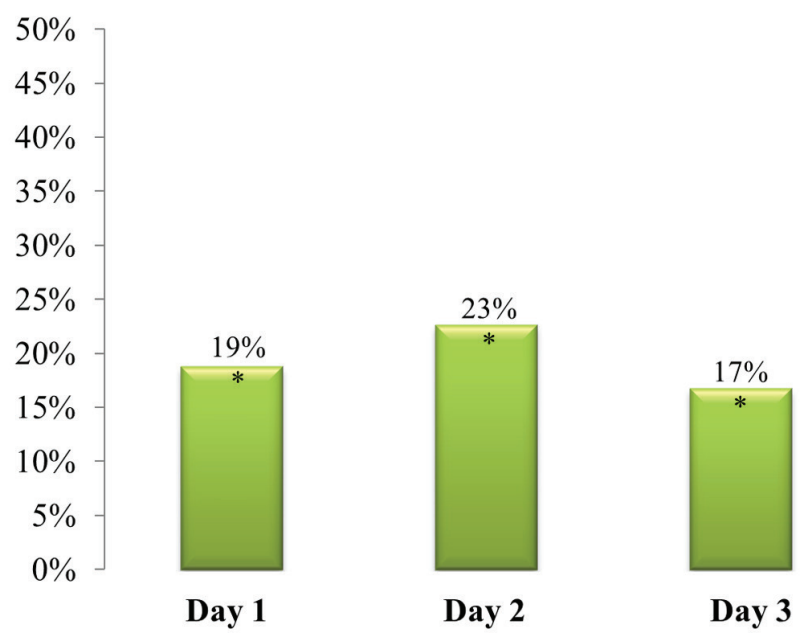

Fig. 3. The medium time spent in the closed-arms for the group receiving association $M S G+$ alprazolam versus receiving only benzodiazepines 
memory impairment $[16,17]$. The deficit of mGluR7 in mice lead to similar results - a reduction of anxiety and spatial memory impairement [18]. Anxiety has been noticed in GAD65 (gene encoding glutamate decarboxylase enzyme, GAD) knocked-out mice. GAD is an enzyme responsible for transforming glutamate in GABA, the main inhibitory neurotransmitter $[19,20]$.

The fact that the anxiogenic effect of the administered MSG was not statistically significant may be a consequence of the insufficient duration of administration (21-24 days) and of the used dosage. The MSG dose choice $(300 \mathrm{mg} /$ $\mathrm{kg}$ ) represents $1 / 50$ from mice LD50 and is only twice the maximum admitted dose per day for human $(150 \mathrm{mg} / \mathrm{kg})$. In general, in research on rodents, the used dosage is 2-10 times larger than those admitted in human, taking into account the higher rate of metabolism.

Both diazepam and alprazolam groups (III, V) presented a significant reduction of the medium time spent in the closed arms of the cross-labyrinth when compared to control group, proving their anxiolytic effect, more intense for diazepam. The similar results were obtained by other authors using alprazolam or diazepam in cross-labyrinth test [11-13].

And finally, as we show on results, the medium time spent in the closed-arms was significantly higher for the groups receiving association MSG+diazepam or MSG+alprazolam (IV,VI), than for the groups receiving only benzodiazepines (diazepam or alprazolam, repectively). This demonstrated a significant antagonism between MSG and the anxiolytics used in the study, which was our working hypothesis. This result is more important as the used MSG dose determined anxiety, even with no statistical significance. The appearance of this phenomenon in our experiment, generates the possibility of a decrease in the effect of the anxyolitics benzodiazepines (such as diazepam and alprazolam) in patients which do not show signs of anxiety aggravated by the MSG-containing consumed foods and drinks.

This antagonism observed between MSG and the anxiolytics used in this study, raises questions on the danger of the extensive use of GLU or its' salts (such as MSG) as flavour enhancers in various processed aliments, regarding the possible reduction of the efficacy of some medicines, some of which extremely used nowadays (i.e. studied anxiolytics).

\section{Conclusions}

The orally administration of $300 \mathrm{mg} / \mathrm{kg}$ MSG (group II), a food additive (E621), for 21 days, slightly increases the degree of anxiety in mice, in cross-labyrinth test but this variation is not significant for the used dose.

The benzodiazepines, diazepam and alprazolam groups (III, V), present a significant reduction the degree of anxiety, proving their anxiolytic effect.

The preexposure to MSG, significantly alters the response to the benzodiazepines therapy, reducing the effect for both alprazolam and diazepam. This decrease is characterized by increased values of time spent in the closed-arms of the cross-labyrinth when compared with groups receiving only diazepam or alprazolam (percentual increases $37 \%, 41 \%, 31 \%$ and $19 \%, 23 \%, 17 \%$, respectively).

Up to date, the subject of possible interactions between dietary sodium monoglutamate (MSG, E621) and the efficacy of drugs is not developed in scientific literature. In consequence, we propose to extend this research theme to some other therapeutic groups.

\section{Acknowledgements}

This paper is supported by the Sectoral Operational Programme Human Resources Development (SOP HRD) 2007-2013, financed from the European Social Fund and by the Romanian Government under the contract number POSDRU/107/1.5/S/82839

\section{References}

1. Beyreuther K., Biesalski H.K., Fernstrom J.D., Grimm P. Consensus meeting: monosodium Glutamate - an update. Eur J Clin Nutr., 2007; 61(3):304-13.

2. Mencinicopschi Gh. Biblia alimentara (Dietary Bible), Edit. Litera International, Bucharest, Romania, 2011: 94-95

3. Guo Y., Wang H.L., Xiang X.H., Zhao Y. The role of glutamate and its receptors in mesocorticolimbic dopaminergic regions in opioid addiction, Neurosci. and Biobehav. Reviews, 2009; (33) 864-873.

4. Buzescu A., Cristea A.N., Avram L., Chiriță C. Experimental Study On The Addictive Behavior Induced By Dietary Glutamic Acid. Practica Medicală, 2013;4(32): 229-233.

5. Cotman C.W., Kahle J.S., Miller S.E. Excitatory aminoacid neurotransmission. In Psychopharmacology: The Fourth Generation of Progress (Bloom F.E., Kupfer D.J.), Raven Press, New York, 1995:75-95.

6. Cortese B.M., Phan, K.L. The role of glutamate in anxiety and related disorders. CNS spectr., 2005; 10(10):820.

7. Simon AB, Gorman JM. Advances in the treatment of anxiety: targeting glutamate. NeuroRx., 2006; 3(1):57-68.

8. Letizia B., Maricla T., Sara C., Alessia L., Nicola Riccardo P., Rosita G., Paolo C. Magnetic resonance imaging volumes of the hippocampus in drug-naive patients with post-traumatic stress disorder without comorbidity conditions. J. Psych. Res., 2008; 42(9):752-62.

9. Cameron O.G., Thyer B.A. Symptom profiles of patients with dsm-hi anxiety disorders. Am. J. Psychiatry, 1986; 143(9):1132-7.

10. Amiel J.M., Mathew S.J. Glutamate and anxiety disorders. Curr. psychiatry rep., 2007; 9(4): 278-83.

11. Kuribara H., Stavinoha W., Maruyama Y. Behavioural pharmacological characteristics of honokiol, an anxiolytic agent present in extracts of magnolia bark, evaluated by an elevated plus-maze test in mice. J Pharm Pharmacol., 1998; 50(7):819-26.

12. Rodgers R.J., Shepherd J.K. Influence of prior maze experience on behaviour and response to diazepam in the elevated plus-maze and light/ dark tests of anxiety in mice. Psychopharm., 1993; 113(2):237-42

13. Prunell M., Escorihuela R.M., Fernández-Teruel A., Núñez J.F., Tobeña A. Anxiolytic profiles of alprazolam and ethanol in the elevated plus-maze test and the early acquisition of shuttlebox avoidance. Pharmacol Res., 1994; 29(1):37-46

14. Ciurea A.V., Edu F.V. Probleme de nocivitate în alimentele uzuale. Edit. Galaxia Gutenberg, Târgu-Lăpuș, 2011, 140-141.

15. Bush R.K., Taylor S.L. Adverse reactions to food and drug additives. In: Atkinson NF Jr, ed. Middleton's Allergy: Principles and Practice. 7th ed. Philadelphia, Pa: Mosby Elsevier; 2008:chap 66.

16. Barkus C., McHugh S.B., Sprengel R., Seeburg P.H., Rawlins J.N.P., Bannerman D.M. Hippocampal NMDA receptors and anxiety: at the interface between cognition and emotion. Eur. J. Pharmacol., 2010; 626(1):49-56.

17. Bergami M., Rimondini R., Santi S., Blum R., Götz M., Canossa M. Deletion of TrkB in adult progenitors alters newborn neuron integration into hippocampal circuits and increases anxiety-like behavior. Proceedings of the National Academy of Sciences, 2008; 105(40):15570-5. 
18. Ahnaou A., Dautzenberg F.M., Geys H., Imogai H., Gibelin A., Moechars D., Drinkenburg W.H. Modulation of group II metabotropic glutamate receptor (mGlu 2) elicits common changes in rat and mice sleep-wake architecture. Eur. J. Pharm., 2009; 603(1):62-72.

19. Kash S.F., Tecott, L.H., Hodge C., Baekkeskov S. Increased anxiety and altered responses to anxiolytics in mice deficient in the $65-\mathrm{kDa}$ isoform of glutamic acid decarboxylase. Proceedings of the National Academy of Sciences, 1999; 96(4):1698-703.

20. Holmes A. Targeted gene mutation approaches to the study of anxietylike behavior in mice. Neuros. \& Biobehavioral Rev., 2001; 25(3):261-73. 